\title{
Improvement of potassium permanganate pretreatment by enzymatic saccharification of rice straw for production of biofuels
}

\author{
Parita Mutrakulcharoen ${ }^{1}$, Peerapong Pornwongthong ${ }^{1}$, Anne Sahithi S.T ${ }^{2}$, Theerawut Phusantisampan ${ }^{3}$, Atthasit Tawai ${ }^{4}$, \\ Malinee Sriariyanun ${ }^{4,5^{*}}$ \\ ${ }^{1}$ Department of Agro-Industrial, Food, and Environmental Technology, Faculty of Applied Science, King Mongkut's University of \\ Technology North Bangkok (KMUTNB), Bangkok, Thailand \\ ${ }^{2}$ School of Biosciences and Technology (SBST), Vellore Institute of Technology (VIT) Vellore, Tamilnadu, India \\ ${ }^{3}$ Department of Biotechnology, Faculty of Applied Science, King Mongkut's University of Technology North Bangkok (KMUTNB), \\ Bangkok, Thailand \\ ${ }^{4}$ Department of Chemical and Process Engineering, The Sirindhorn International Thai-German Graduate School of Engineering \\ (TGGS), King Mongkut's University of Technology North Bangkok (KMUTNB), Bangkok, Thailand \\ ${ }^{5}$ Biorefinery and Process Automation Engineering Center (BPAEC), King Mongkut's University of Technology North Bangkok \\ (KMUTNB), Bangkok, Thailand
}

\begin{abstract}
Commonly, the agricultural waste, i.e. lignocellulosic biomass is disposed through combustion causing air pollution with production of PM2.5 and PM10 particles. However, it has been found that these biomasses can be used as source for the production of biofuels and other valuable biochemicals. Though deconstruction of lignocellulosic biomass is challenging due to its complex structure. In this study, rice straw (RS) was pretreated using potassium permanganate $\left(\mathrm{KMnO}_{4}\right)$ to enhance the enzymatic saccharification efficiency. The study was carried out by varying the operational factors in pretreatment, including temperature $\left(30-90^{\circ} \mathrm{C}\right)$, time $(30-360 \mathrm{~min})$ and concentration of $\mathrm{KMnO}_{4}(0.5-3.0$, \% w/v), respectively, based on Box-Behnken design (BBD). Through multi-regression analysis of the experimental data obtained after pretreatment, the optimum conditions were determined. The optimum conditions for temperature, time and potassium permanganate concentration were $48.09^{\circ} \mathrm{C}, 360 \mathrm{~min}$, and $1.36 \% \mathrm{w} / \mathrm{v}$, respectively. The saccharifications of pretreatment and untreated rice straw were carried out using Cellic Ctec2. The reducing sugar was determined by using DNS method and the yields of the untreated and pretreated RS were 32.38 and $49.011 \mathrm{mg} / \mathrm{mL}$, respectively. The results showed that the sugar for pretreated RS were 1.51 fold times higher compared to untreated RS. Therefore, this work illustrates the pretreatment efficiency for $\mathrm{KMnO} 4$ to enhance the reducing sugar yield during saccharification, which can be used for biofuel and value-added product productions.
\end{abstract}

Keywords. Potassium permanganate, Pretreatment, Enzymatic saccharification, Biorefinery, Biofuels

\section{Introduction}

Lignocellulosic biomass is an inedible organic material source having the potential to be utilized as an alternative source for fossil fuels. Common lignocellulosic biomass includes forest residues, agricultural residues and dedicated crops. It has been reported in 2013 that 62 million tons of waste biomass are generated from the agricultural activities of Thailand. The biomass waste accounts for 13.3 million tons and is likely to increase further in coming years. Increase in the waste generation is related to the continuous increase in the food demand due to the rapid growth of population. The industrial growth is also proportional to the population growth but it greatly affects the environments [1]. It was reported that the air was highly polluted in Thailand (2007-2016) due to the presence of particulate matters (PM10 an PM2.5) [2]. One of the causal agents of these polluted particles was due to the incineration of waste biomass generated after the harvesting seasons. This tradition is being followed worldwide to prepare the soil for next harvesting season. Incinerations of agricultural residues also increase in the emission of carbon dioxide $\left(\mathrm{CO}_{2}\right)$, an important of greenhouse gas.

To lessen combustion of agricultural waste, lignocellulose biomass has been proposed to utilized as raw materials for productions of biofuels and biochemical [3]. Lignocellulose is composed of cellulose, hemicellulose, and lignin. Each of this component varies in different ratio from biomass to biomass. In general lignocellulose composes of cellulose, hemicellulose and lignin in the range of 40$50 \%, 20-30 \%$, and $10-25 \%$, respectively [4-5]. Cellulose is a polysaccharide chain of glucose units linked via $\beta$ -

*Corresponding author: macintous@gmail.com 
1,4 glycosidic bonds. On the other hand, hemicellulose is a polysaccharide with $\mathrm{C}_{5}$ sugars (xylose and arabinose) and $\mathrm{C}_{6}$ sugars (glucose, galactose, and mannose). Lignin is an organic polymer composed of phenylpropane units. [6-8]. However due to the recalcitrance nature of the lignocellulosic biomass, it has been a challenge for the researchers for converting biomass to biofuel and other by-products. Conversion of lignocellulose to the valuable products, therefore requires three major steps such as pretreatment, saccharification, and fermentation. [9-11]

In recent years, several pretreatment methods have been developed for the fractionation of lignocellulosic biomass. Pretreatment methods include physical pretreatment (mechanical size reduction, pyrolysis), chemical pretreatment (ozonolysis, acid pretreatment, alkali pretreatment, oxidative delignification), physicochemical pretreatment (stream explosion, ammonia fiber explosion, microwave pretreatment, carbon dioxide explosion, wet oxidation) and biological pretreatment (fungus and bacteria) [4], [12], [13-17]. Pretreatment is an essential step prior to saccharification process. Pretreatment leads to fractionation of biomass through solubilization and structure modification of lignin and hemicellulose, respectively. After pretreatment, cellulose is converted to glucose by the cellulase enzymes due the ease in accessibility. Though pretreatment methods have advantages in the fractionation of biomass, each pretreatment method has its own disadvantage, for instance, some pretreatment methods require high energy or use toxic substances or have high operational cost [4].

Among the different chemical pretreatment methods, acid and alkali pretreatments are studied worldwide. However strong acid and alkaline are considered to be harmful to both the operator and the environment. In addition, acid pretreatment degrades sugars to inhibitory compounds (furfural and 5hydrozymethylfurfural [18]) to the functions of enzymes, and therefore decreases the conversion efficiency from cellulose to glucose monomers. On the other hand, lignin and hemicellulose is solubilized completely or partially during alkaline pretreatment, respectively [17-20]. Lee et. al., reported delignification and saccharification efficiency of $89.4 \%$ and $75.9 \%$ in corn stover after diluted alkaline pretreatment [21]. On the other hand, Ravindran et. al., reported delignification and cellulose recovery of $46 \%$ and $98 \%$, from $\mathrm{KMnO}_{4}$ pretreated spent coffee waste, respectively [22]. Ma et. al., reported $46.79 \%$, and $81.47 \%$ removal of lignin and hemicellulose from pretreated corncob using $\mathrm{KMnO}_{4}$ [23].

In this study, $\mathrm{KMnO}_{4}$ pretreatment of the rice straw was carried out to improve saccharification efficiency. $\mathrm{KMnO}_{4}$ is inexpensive, readily available, and less toxic compared to acids such as sulphuric acid and it is one of the common chemicals in kitchen application. $\mathrm{KMnO}_{4}$ pretreatment of rice straw was carried out by varying the reaction time, temperature and concentration of $\mathrm{KMnO}_{4}$. The $\mathrm{KMnO}_{4}$ pretreatment conditions were optimized based on Response Surface Methodology (RSM) with Box Behnken Design (BBD). The operational parameters were optimized through multiple regression analysis that generated the mathematical model. The optimal condition of pretreatment obtained from the model was validated by experiments to confirm the reliability of the predicted pretreatment conditions.

\section{Material and methods}

\subsection{Raw materials}

Rice straw was obtained from Phra Nakhon Si Ayutthaya province, Thailand. The collected rice straw was subjected to particle reduction using food processor after drying in a hot air oven at $60^{\circ} \mathrm{C}$ to remove moisture. The dried sample was screened through 20 mesh sized aluminium sieve for the homogeneous nature of particle size.

Cellic Ctec2, a commercial cellulase enzyme, was obtained from Sigma-Aldrich (aqueous solution, density $1.15 \mathrm{~g} / \mathrm{mol}$ ). This enzyme is a cocktail mixture of cellulases, ß-glucosidases and hemicellulase. Potassium permanganate $\left(\mathrm{KMnO}_{4}\right)$, and other analytical reagents were obtained from Alex Finechem (Univar).

\subsection{Pretreatment of rice straw}

Pretreatment of rice straw using $\mathrm{KMnO}_{4}$ was carried out under different reaction time, temperature and concentration of $\mathrm{KMnO}_{4}$. A solid loading of $10 \%(1: 10$ w/w) was maintained throughout the study. Firstly, the testing ranges of pretreatment factors, such as reaction time, temperature, and concentration of $\mathrm{KMnO}_{4}$ were varied to $2-8 \mathrm{~h}, 30-75^{\circ} \mathrm{C}$, and $1-4 \% \mathrm{w} / \mathrm{v}$, respectively to preliminarily evaluate the boundary of testing ranges for RSM experiments. Secondly, after the determination of the suitable testing ranges for RSM, the experimental designed for optimization was carried out based on BBD. Three independent variables, composing of time (30-360 $\mathrm{min})$, temperature $\left(30-90^{\circ} \mathrm{C}\right)$, and $\mathrm{KMnO}_{4}$ concentration $(0.5-3 \% \mathrm{w} / \mathrm{v})$, were set with three testing levels $(-1,0$, and +1$)$ as summarized in Table 1 . The pretreatments of rice straw were carried out by following the individual runs as summarized in Table 2. The pretreated solid biomass was harvested by filtration with No.1. Whatman filter paper to remove the liquid hydrolysate. After collection of the hydrolysate, the solids were washed using deionized water until $\mathrm{pH}$ was neutral. The pretreated solids were dried in a hot air oven at $60^{\circ} \mathrm{C}$ until the weight was constant. The dried pretreated and untreated samples were subjected to enzymatic saccharification, and reducing sugars released from hydrolysis reactions were analysed by DNS assay to determine the pretreatment efficiency.

The amounts of reducing sugars obtained from each experimental runs were analyzed by ANOVA analysis to observe the effect of pretreatment parameters on yields of reducing sugars with the significant level of P-value $<0.05$ for the model and term model. The mathematical model derived from ANOVA analysis was then generated to predict the optimal pretreament condition. The correlation coefficiency $\left(\mathrm{R}^{2}\right)$ was calculated to 
confirm the reliability of the predicted model. All statistical analysis of the experimental results obtained for the BBD design were analyzed using Design-Expert software (version 7.0)

Table 1. Independent variables in pretreatment condition of rice straw based on RSM.

\begin{tabular}{|l|c|c|c|c|}
\hline \multirow{2}{*}{$\begin{array}{c}\text { Independent } \\
\text { variable }\end{array}$} & \multirow{2}{*}{$\begin{array}{c}\text { Coded } \\
\text { symbols }\end{array}$} & \multicolumn{3}{|c|}{ Levels } \\
\cline { 3 - 5 } & $\mathrm{X}_{1}$ & 30 & $\mathbf{0}$ & $+\mathbf{1}$ \\
\hline Time (min) & $\mathrm{X}_{2}$ & 30 & 60 & 360 \\
\hline Temperature $\left({ }^{\circ} \mathrm{C}\right)$ & $\mathrm{X}_{3}$ & 0.50 & 1.75 & 3.00 \\
\hline Concentration $(\%)$ & &
\end{tabular}

Table 2. RSM experiment design for $\mathrm{KMnO}_{4}$ pretreatment of rice straw

\begin{tabular}{|c|c|c|c|c|}
\hline \multirow[t]{2}{*}{ Run } & \multicolumn{3}{|c|}{ Pretreatment condition } & \multirow{2}{*}{$\begin{array}{c}\text { Reducing } \\
\text { sugar } \\
(\mathrm{mg} / \mathrm{mL})\end{array}$} \\
\hline & $\begin{array}{c}X_{1}: \\
\text { Time } \\
\text { (min) }\end{array}$ & $\begin{array}{c}\mathbf{X}_{2}: \\
\text { Temperature } \\
\left({ }^{\circ} \mathrm{C}\right)\end{array}$ & $\begin{array}{c}\mathrm{X}_{3}: \\
\text { Concentration } \\
(\%)\end{array}$ & \\
\hline 1 & 195 & 60 & 1.75 & 47.86 \\
\hline 2 & 195 & 30 & 0.50 & 43.36 \\
\hline 3 & 360 & 60 & 3.00 & 30.53 \\
\hline 4 & 30 & 60 & 0.50 & 42.60 \\
\hline 5 & 360 & 90 & 1.75 & 52.70 \\
\hline 6 & 360 & 60 & 0.50 & 45.25 \\
\hline 7 & 30 & 30 & 1.75 & 43.99 \\
\hline 8 & 195 & 60 & 1.75 & 47.86 \\
\hline 9 & 195 & 30 & 3.00 & 31.25 \\
\hline 10 & 195 & 60 & 1.75 & 45.59 \\
\hline 11 & 30 & 60 & 3.00 & 31.61 \\
\hline 12 & 195 & 60 & 1.75 & 51.02 \\
\hline 13 & 195 & 90 & 0.50 & 45.72 \\
\hline 14 & 30 & 90 & 1.75 & 46.68 \\
\hline 15 & 360 & 30 & 1.75 & $49 / 04$ \\
\hline 16 & 195 & 60 & 1.75 & 49.75 \\
\hline 17 & 195 & 90 & 3.00 & 30.36 \\
\hline
\end{tabular}

\subsection{Enzymatic hydrolysis}

Enzymatic saccharification process was carried out for untreated and pretreated rice straw to determine the efficiency of $\mathrm{KMnO}_{4}$ pretreatment. For each reaction, 0.2 $\mathrm{g}$ of the biomass (untreated and pretreated) was added to $8 \mathrm{~mL}$ of citrate buffer $(50 \mathrm{mM}, \mathrm{pH} 4.8)$ in a $50 \mathrm{~mL}$ centrifuge tube. In addition, $80 \mu \mathrm{L}$ of $2 \mathrm{M}$ sodium azide were added to avoid the contamination of the samples due to growth of microbes during saccharification process. To the mixture, $1.4 \mu \mathrm{L}$ Cellic Ctec 2 enzyme mix was added. The mixed samples were placed in a shaking incubator with the temperature and mixing speed at $50^{\circ} \mathrm{C}$ and $150 \mathrm{rpm}$, respectively. Enzymatic saccharifications of the untreated and treated rice straw were carried out for $72 \mathrm{~h}$. After $72 \mathrm{~h}$, the liquid hydrolysate was taken from the mixture by centrifugation at $10,000 \times \mathrm{g}$ for $5 \mathrm{~min}$. The supernatant was collected for the determination of the reducing sugar by following the modified dinitrosalicylic acid (DNS) method.

\subsection{Analysis of reducing sugar}

The reducing sugar concentration in the hydrolysate was measured by following the dinitrosalicylic acid (DNS) method. In a $1.5 \mathrm{~mL}$ centrifuge tube, $50 \mu \mathrm{L}$ of hydrolysate and 3,5-dinitrosalicylic acid (DNS) reagent was added. The tubes were incubated at $95^{\circ} \mathrm{C}$ using a water bath for $5 \mathrm{~min}$. The tubes were allowed to cooled down in an ice bath for $5 \mathrm{~min}$. After cooling of the sample, $1 \mathrm{~mL}$ of distilled water was added and mixed with a vortex shaker. After the samples were prepared, the reducing sugar was analyzed using UV/Vis spectrophotometer at $540 \mathrm{~nm}$. The concentration of the reducing sugar $(\mathrm{mg} / \mathrm{mL})$ was calculated by using a standard glucose curve.

\section{Result and discussion}

\subsection{Determine the testing levels of pretreatment parameters}

The effects of reaction, temperature and $\mathrm{KMnO}_{4}$ concentration on pretreatment of rice straw were preliminary evaluated to set the boundary of testing level for RSM. Three sets of experiments to pretreat rice straw were conducted by varying each pretreatment factor at a time (Figure 1). Firstly, the pretreatment time was varied between 2 to $8 \mathrm{hr}$, and the pretreatment temperature was fixed at $40^{\circ} \mathrm{C}$ using $2 \%(\mathrm{w} / \mathrm{v}) \mathrm{KMnO}_{4}$ (Figure 1a). Secondly, the pretreatment temperature was varied between 30 to $75^{\circ} \mathrm{C}$, and the pretreatment time was fixed at $4 \mathrm{~h}$, using $2 \%(\mathrm{w} / \mathrm{v}) \mathrm{KMnO}_{4}$ (Figure $\left.1 \mathrm{~b}\right)$. Thirdly, the $\mathrm{KMnO}_{4}$ concentration was varied between $1-4 \%$, and the pretreatment time and temperature were set at $40^{\circ} \mathrm{C}$ for 4 h (Figure 1c). It was observed from Fig. 1a that the reducing sugar yield varied for pretreated samples at different reaction time $(2-8 \mathrm{~h})$. The reducing sugar yields increased 1.15 fold times ( 18.36 to $21.13 \mathrm{mg} / \mathrm{mL}$ ), when the reaction time was varied between $(2-6 \mathrm{~h})$ and this increasing yield was saturated at between 6-8 h. Therefore, the upper boundary level of pretreatment time of $6 \mathrm{~h}$ was selected for RSM experiments. Next, the testing boundary level of pretreatment temperature (30$75^{\circ} \mathrm{C}$ ) on saccharification efficiency was evaluated (Fig. 1b). Maximum reducing sugar yield of $23.68 \mathrm{mg} / \mathrm{mL}$ was obtained when rice straw was pretreated at $60^{\circ} \mathrm{C}$. As the pretreatment temperature was increased to $75^{\circ} \mathrm{C}$, it was found that the reducing sugar yield decreased 1.01 fold times. Therefore, it was implied as similar to the effect of reaction time that, sugars were degraded at higher temperature. Due to the lower effect of temperature on reducing sugar from rice straw pretreated at $75^{\circ} \mathrm{C}$. The temperature for $\mathrm{BBD}$ design was considered to be $30-90^{\circ} \mathrm{C}$. Meanwhile, the independent effect of KMNO4 concentration on reducing sugar yield during saccharification of pretreated rice straw was also investigated (Fig.1c). The concentration of $\mathrm{KMNO}_{4}$ was varied from $1-4 \% \mathrm{w} / \mathrm{v}$. It was noted that the reducing sugar yield was higher initially $(27.04 \mathrm{mg} / \mathrm{mL})$, when the $\mathrm{KMnO}_{4}$ concentration was maintained at $1 \% \mathrm{w} / \mathrm{v}$ 
(a)

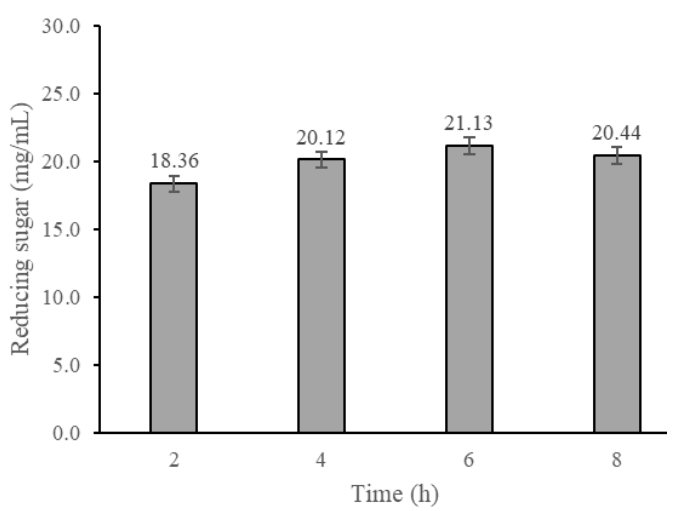

(b)

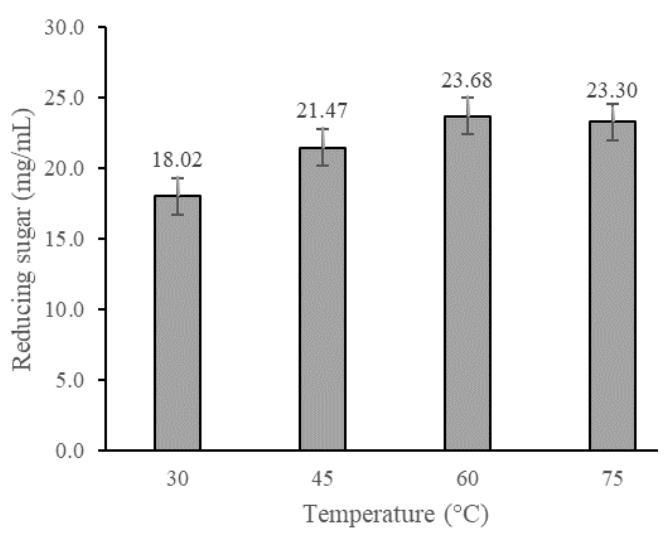

(c)

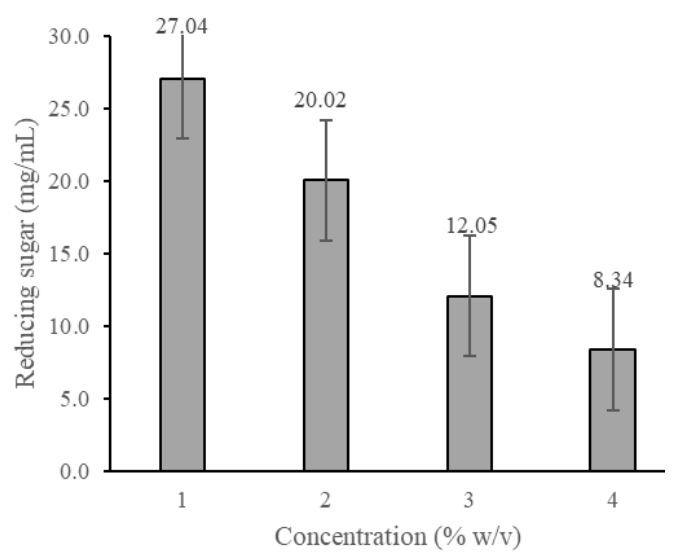

Fig. 1. Effect of pretreatment time, temperature and $\mathrm{KMnO}_{4}$ concentration on the enzymatic hydrolysis of rice straw. (A) The pretreatment was conducted using $2 \%(\mathrm{w} / \mathrm{v}) \mathrm{KMnO}_{4}$ at $40^{\circ} \mathrm{C}$, (B) The pretreatment was conducted using $2 \%(\mathrm{w} / \mathrm{v})$ for 4 hours and (C) The pretreatment were conducted at $40^{\circ} \mathrm{C}$ for 4 hours.

However, as the $\mathrm{KMNO}_{4}$ concentration increased from $1-4 \% \mathrm{w} / \mathrm{v}$, the reducing sugar yield decreased 3.24 fold times $(27.04-8.34 \mathrm{mg} / \mathrm{mL})$. Thus, the saccharification efficiency was negatively impacted by the increase in concentration of $\mathrm{KMnO}_{4}$ during pretreatment. Therefore, the $\mathrm{KMnO}_{4}$ concentration in the BBD design was varied from $0.5-3.0 \% \mathrm{w} / \mathrm{v}$. The results or released reducing sugars showed that the parameters with the preliminary tested ranges were not statistically significant. Therefore, the independent variables levels were modified and used in the BBD design of RSM study (Table 1).

Overall, it was observed that the testing levels of independent variables (pretreatment time, pretreatment temperature and $\mathrm{KMnO}_{4}$ concentration) had effects on enzymatic saccharifications of rice straw. This finding was in agreement with different studies carried out by several published works. Romero et al performed pretreatment of rapeseed straw using $\mathrm{FeCl}_{3}$ under various conditions of time, temperature and $\mathrm{FeCl}_{3}$ concentration. A direct correlation between reducing sugar content and operational parameters were reported [24]. In addition, Dahunsi et al performed alkali pretreatment of pineapple peel and reported similar correlation between reducing sugar contents and operational parameters [25].

\subsection{RSM design and experimental testing}

The RSM experiment has been proposed as an effective method of designing and conducting experiments to determine the optimal condition for production process. The RSM study assists evaluation of effects of individual independent variables and their interactions on the dependent variables. RSM reduces the numbers of experimental runs, in turn, reducing the experimental cost. Furthermore, RSM is often used for generation of the empirical model and prediction of the desired response under different conditions of independent variables [15]. In recent years, several studies have illustrated the significance of using RSM in reducing the experimental runs and improving the process efficiency by varying numbers of parameters conditions simultaneously [26-27].

In the present study, the RSM study was carried out by generating a BBD matrix (Table 3 ) with three testing levels $(-1,0,+1)$ for three pretreatment parameters (time, temperature and $\mathrm{KMnO}_{4}$ concentration) (Table 1) with a total 17 experimental runs (Table 2). The statistical analysis was carried out using Design-Expert software (ver 7.0.0) throughout the whole study. The experimental data were used in determining the regression coefficient $(\beta)$ using least square method. In addition, the second order model was generated from the experimental data. The optimum pretreatment conditions were determined for achieving maximum reducing sugar yield from the multi-regression analysis of the second-order model. The second order model significance were evaluated by (a) determining the coefficient of determination $\left(\mathrm{R}^{2}\right)$, (b) significance of model terms in ANOVA, and (c) non-significance of the lack-of-fit. The second-order model is generally considered to be significant when the $\mathrm{R}^{2}$ value is greater than 0.9. In this study, the $\mathrm{R}^{2}$ value of the second-order model was 0.9646 implying lower variance between the experimental data and the representative model. In fact, the $\mathrm{R}^{2}$ value of higher than 0.9 does not always indicate the significance of the model. Therefore, ANOVA was 
carried out to determine the significance of the secondorder model (Table 3).

Table 3. ANOVA analysis of the second-order model obtained from RSM experiments.

\begin{tabular}{|c|c|c|c|c|c|}
\hline Source & $\begin{array}{c}\text { Sum of } \\
\text { Squares }\end{array}$ & df & $\begin{array}{c}\text { Mean } \\
\text { Squares }\end{array}$ & F Value & $\begin{array}{c}\text { P-value } \\
\text { Prob }> \\
\text { F }\end{array}$ \\
\hline Model & 855.98 & 3 & 285.33 & 80.13 & $<0.0001$ \\
\hline A-Time & 19.77 & 1 & 19.77 & 5.55 & 0.0348 \\
\hline C-Conc & 352.76 & 1 & 352.76 & 99.07 & $<0.0001$ \\
\hline C $^{2}$ & 483.46 & 1 & 483.46 & 135.76 & $<0.0001$ \\
\hline Residual & 46.29 & 13 & 3.56 & & \\
\hline Lack of Fit & 29.14 & 9 & 3.24 & 0.76 & 0.6677 \\
\hline Pure Error & 17.15 & 4 & 4.29 & & \\
\hline Cor Total & 902.27 & 16 & & & \\
\hline
\end{tabular}

The ANOVA results indicated that the model with Fvalue of 80.13 was statistically significant $(\mathrm{P}<0.05)$. There was only a $0.01 \%$ chance that a "Model F-value" could occur due to noise (Table 3). Furthermore, the model terms of time, and $\mathrm{KMnO}_{4}$ concentration were also significant (since $\mathrm{P}<0.05$ ). Based on the same criteria, it was noted that neither the interaction terms for time, temperature and $\mathrm{KMnO}_{4}$ concentration was significant. However, significance for the quadratic term of $\mathrm{KMnO}_{4}$ concentration was seen. Therefore, the accuracy of the second-order model was improved by including the model terms that were significant. Additionally, the model significance was also evaluated through determination of the lack-of-fit test. The F-value of 0.76 implied that the lack of fit is not significant relative to the pure error. There is a $66.77 \%$ chance that a "Lack of Fit F-value" this large could occur due to noise. Therefore, the second order model was considered significant since the lack of fit was not significant and the errors were normally distributed. Therefore, through evaluation of the second-order model, time and $\mathrm{KMnO}_{4}$ concentration were considered to have more effect on the reducing sugar yield released during saccharification after pretreatment of rice straw.

\subsection{Effects of pretreatment parameters on enzymatic saccahrification and validation of mathematical models for pretreatment}

The effect of each significant model terms (time, and $\mathrm{KMnO}_{4}$ concentration) on response (reducing sugar concentration) was monitored (Fig. 2). In addition, the interaction effects of the independent variables on response were visualized through three-dimensional contour plots (Fig. 3). It can be seen that the reducing sugar yield obtained from saccharification was increased when rice straw was pretreated with longer pretreatment time (Fig 2a). Under variations of $\mathrm{KMnO}_{4}$ concentration, the reducing sugar yield was increased when the $\mathrm{KMnO}_{4}$ concentration increased. However, when $\mathrm{KMnO}_{4}$ concentration was higher than $1.36 \%$, the more $\mathrm{KMnO}_{4}$ concentration, the less reducing sugar yields (Fig 2b). Meanwhile, interaction effects of time, temperature, and $\mathrm{KMnO}_{4}$ resulted in similar observation (Fig 3). (a)

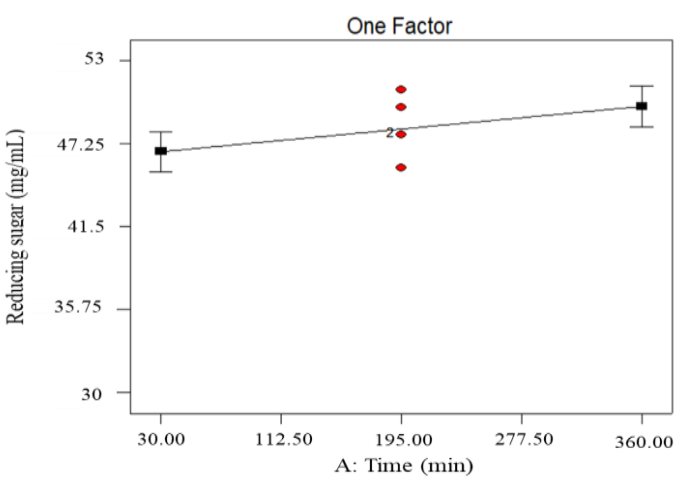

(b)

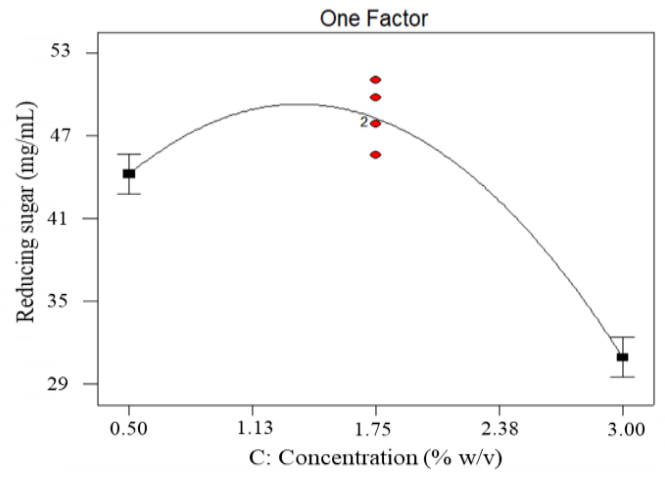

Fig. 2. The relationship between each pretreatment factor, including (A) pretreatment time (min) and (B) $\mathrm{KMnO}_{4}$ concentration $(\%)$ and reducing sugar concentration $(\mathrm{mg} / \mathrm{mL})$ obtained from pretreated rice straw.

(a)

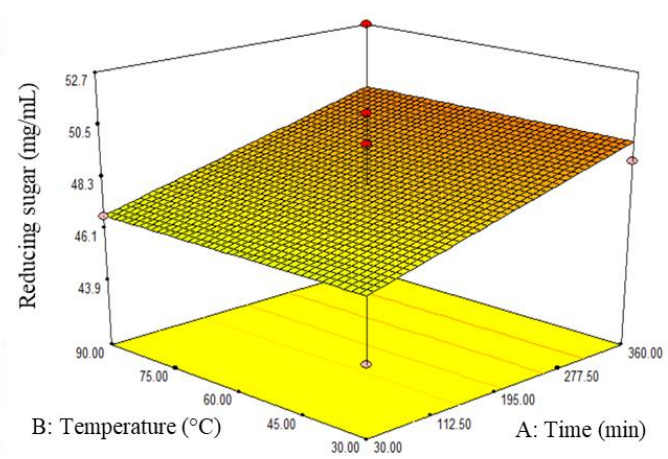

(b)

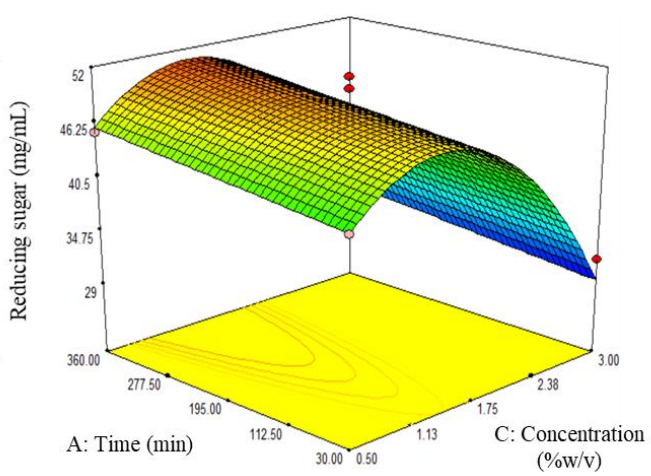

Fig. 3. Response surface plot represents the effects of pretreatment factors on reducing sugar yield $(\mathrm{mg} / \mathrm{mL})$. (A) pretreatment time vs. pretreatment temperature and (B) $\mathrm{KMnO}_{4}$ concentration vs pretreatment time. 
Through ANOVA analysis of the second order model, the relationships of pretreatment conditions on reducing sugar concentrations were represented in the form of mathematical model (Table 4). The optimum pretreatment conditions for obtaining maximum reducing sugar yield at $50.88 \mathrm{mg} / \mathrm{mL}$ were predicted and summarized in Table 4 . To confirm the reliability of this model, the rice straw was pretreated again using this predicted optimum pretreatment conditions. A reducing sugar yield of $49.01 \mathrm{mg} / \mathrm{mL}$ was obtained from the enzymatic saccharification of the pretreated rice straw under optimum pretreatment conditions. Thus, there was only $3.49 \%$ error obtained from experimental result compared to predicted yield from the model, indicating high validity of RSM model. The influence of time and $\mathrm{KMnO}_{4}$ concentration on reducing sugar yield were in agreement with studies carried out by Romero at al. [24] and Zhao et al. [28]. Therefore, it was found that increase in reaction time with optimum $\mathrm{KMnO}_{4}$ concentration can improve enzymatic saccharification efficiency.

Table 4. Mathematical models and optimal pretreatment condition obtained from RSM experiment.

\begin{tabular}{|l|c|c|c|c|}
\hline \multicolumn{3}{|c|}{ Optimal pretreatment parameter } & $\begin{array}{c}\text { Reducing sugar yield } \\
(\mathbf{m g} / \mathbf{m L})\end{array}$ \\
\hline $\begin{array}{c}\text { Time } \\
(\mathbf{m i n})\end{array}$ & $\begin{array}{c}\text { Temperature } \\
\left({ }^{\circ} \mathbf{C}\right)\end{array}$ & $\begin{array}{c}\mathbf{K M n O}_{4} \\
\text { Concentration } \\
(\% \text { w/v) }\end{array}$ & Predicted & Experimental \\
\hline 360 & 84.09 & 1.36 & 50.88 & 49.01 \\
\hline $\begin{array}{l}\text { Mathematical Model } \\
\text { Reducing Sugar }=+34.77502+9.52745 \times 10-3 \times \text { Time }+ \\
18.62003 \times \text { Conc }-6.83781 \times \text { Conc }^{2}\end{array}$ \\
\hline
\end{tabular}

\section{Conclusion}

The present study was focused on the objective to obtain maximum reducing sugar from rice straw during saccharification after pretreatment using $\mathrm{KMnO}_{4}$. These reducing sugars have the potential to be converted to biofuels and other valuable products. The individual effect of the operational parameters (time, temperature and $\mathrm{KMnO}_{4}$ concentration) was studied based on RSM with BBD. The optimum pretreatment conditions for time, temperature, and $\mathrm{KMnO}_{4}$ concentration were $84.09^{\circ} \mathrm{C}, 360 \mathrm{~min}$, and $1.36 \%$ (concentration of $\mathrm{KMnO}_{4}$ ). The maximum reducing sugar yield from pretreated rice straw under optimum conditions were $49.01 \mathrm{mg} / \mathrm{mL}$. In conclusion, $\mathrm{KMnO}_{4}$ pretreatment had significant effect on rice straw to improve the saccharification efficiency and had potential to be applied in further uses due to its less toxicity and cost.

\section{Acknowledgement}

The authors would like to thank the King Mongkut's University of Technology North Bangkok (Grant
Contract No. KMUTNB-BasicR-64-37) for financial support of this work.

\section{References}

1. A. Sukkaew, P. Boonsong, S. Thongpradistha, M. Intan, Physical and Chemical Pretreatment of Lignocellulosics in Pineapple (Ananus comosus) Peels Dried for Investment, AIP Conference Proceedings, 1868, 090001 (2017)

2. R. Janta, K. Sekiguchi, R. Yamaguchi, K. Sopajaree, B. Plubin, T. Chetiyanukornkul, Spatial and Temporal Variations of Atmospheric PM10 and Air Pollutants Concentration in Upper Northern Thailand During 2006-2016, Applied Science and Engineering Progress, 13,3 (2020): 256-267

3. EJ. Panakkal, M Sriariyanun, J. Ratanapoompinyo P. Yasurin, K. Cheenkachorn, W. Rodiahwati, P. Tantayotai, Influence of Sulfuric Acid Pretreatment and Inhibitor of Sugarcane Bagasse on the Production of Fermentable Sugar and Ethanol, Applied Science and Engineering Progress, 15,1(2022)

4. S. Cheng, P. Mutrakulcharoen, S. Chuetor, K. Cheenkachorn, T. Tantayotai, E. J. Panakkal, M. Sriariyanun, Recent Situation and Progress in Biorefining Process of Lignocellulosic Biomass: Toward Green Economy, Applied Science and Engineering Progress, 13,1 (2020): 3-10

5. R. Akkharasinphonrat, T. Douzou, M. Sriariyanun, Development of ionic liquid utilization in biorefinery process of lignocellulosic biomass, King Mongkut's University of Technology North Bangkok International Journal of Applied Science and Technology, 10,2 (2017): 89-96

6. H. Chen, J. Liu, X. Chang, D. Chen, Y. Xue, P. Liu, H. Lin and S. Han, A review on the pretreatment of lignocellulose for high-value chemicals, Fuel Processing Technology, 160 (2017): 196-206

7. A.K. Obeng, D. Premjet, and S. Premjet, Fermentable Sugar Production from the Peels of Two Durian (Durio zibethinus Murr.) Cultivars by Phosphoric Acid Pretreatment, Resources, 7,4 (2018): 60

8. P. Moyer, K. Kim, N. Abdoulmoumine, S.C. Chmely, B.K. Long, D.J. Carrier, and N. Labbé, Structural changes in lignocellulosic biomass during activation with ionic liquids comprising 3methylimidazolium cations and carboxylate anions, Biotechnology for Biofuels. 11 (2018): 265

9. MP. Gundupalli, YS. Cheng, S. Chuetor, D. Bhattacharyya, M. Sriariyanun. Effect of Dewaxing on saccharification and ethanol production from different lignocellulosic biomass. Bioresource Technology. 125596.

10. M. Sriariyanun and K. Kitsubthawee. 2020. Trends in Lignocellulosic Biorefinery for Production of Value-added Biochemicals. Applied Science and Engineering Progress, 13, 2 (2020) 
11. P.L. Show and M. Sriariyanun. 2020. Prospect of Liquid Biphasic System in Microalgae Research. Applied Science and Engineering Progress, 14, 2 (2020): 1-2

12. L. Shao, H. Chen, Y. Li, J. Li, G. Chen, G. Wang, Pretreatment of corn stover via sodium hydroxideurea solutions to improve the glucose yield, Bioresource Technology, 307 (2020)

13. Y.S. Cheng, Z.Y. Wu, and M. Sriariyanun, Evaluation of Macaranga tanarius as a biomass feedstock for fermentable sugars production, Bioresource Technology, 294 (2019): 122195

14. A. Boontum, J. Phetsom, W. Rodiahwati, K. Kitsubthawee, and T. Kuntothom. Characterization of Diluted-acid Pretreatment of Water Hyacinth, Applied Science and Engineering Progress, 12, 4 (2019): 253-263

15. K. Rattanaporn, S. Roddecha, M. Sriariyanun, and K. Cheenkachorn. Improving Saccharification of Oil Palm Shell by Acetic Acid Pretreatment for Biofuel Production, Energy Procedia, 141 (2017): 146-149

16. K. Rattanaporn, P. Tantayotai, T. Phusantisampan, P. Pornwongthong, and M. Sriariyanun, Organic acid pretreatment of oil palm trunk: effect on enzymatic saccharification and ethanol production, Bioprocess and Biosystems Engineering, 41, 4 (2018), 467-477

17. K. Cheenkachorn, T. Douzou, S. Roddecha, P. Tantayotai, and M. Sriariyanun, Enzymatic Saccharification of Rice Straw under Influence of Recycled Ionic Liquid Pretreatments, Energy Procedia, 100 (2016): 160-165

18. P. Rachmontree, T. Douzou, K. Cheenkachorn, M. Sriariyanun and K. Rattanaporn, Furfural: A sustainable platform chemical and fuel Applied Science and Engineering Progress, 13, 1 (2020): 310

19. S. Sahu and K. Pramanik, Evaluation and Optimization of Organic Acid Pretreatment of Cotton Gin Waste for Enzymatic Hydrolysis and
Bioethanol Production., Applied Biochemistry and Biotechnology, 186, 4 (2018): 1047-1060

20. S.M.G. Saerens, F.R. Delvaux, K.J. Verstrepen and J.M. Thevelein, Production and biological function of volatile esters in Saccharomyces cerevisiae, Microb Biotechnology, 3, 2 (2010): 165-177

21. J.W. Lee, J.Y. Kim, H.M. Jang, M.W. Lee and J.M. Park, Sequential dilute acid and alkali pretreatment of corn stover: Sugar recovery efficiency and structural characterization, Bioresource Technology, 188 (2015): 296-301

22. R. Ravindran, S. Jaiswal, N.A. Ghannam and A.K. Jaiswal, Evaluation of ultrasound-assisted potassium permanganate pretreatment of spent coffee waste, Bioresource Technology, 224 (2017): 680-687

23. I. Romero, J.C. López-Linares, M. Moya and E. Castro, Optimization of sugar recovery from rapeseed straw pretreated with $\mathrm{FeCl}_{3}$, Bioresource Technology, 268 (2018): 204-211

24. L. Ma, Y. Cui, R. Cai, X. Liu, C. Zhang and D. Xiao, Optimization and evaluation of alkaline potassium permanganate pretreatment of corncob, Bioresource Technology, 180 (2015): 1-6

25. S.O.Dahunsi, Liquefaction of pineapple peel: Pretreatment and process optimization, Energy, 185 (2019): 1017-1031

26. LK. Akula, RK Oruganti, D. Bhattacharyya and KK. Kurilla. Treatment of Marigold Flower Processing Wastewater Using a Sequential BiologicalElectrochemical Process. Applied Science Engineering Progress, 14,3 (2021): 525-542

27. P. Amnuaycheewa, W. Rodiahwati, P. Sanvarinda, K. Cheenkachorn, A. Tawai and M. Sriariyanun, Effect of Organic Acid Pretreatment on Napier Grass (Pennisetum purpureum) Straw Biomass Conversion, Applied Science and Engineering Progress, 10,2 (2017): 107-117

28. X. Zhao, L. Wang, X. Lu and S. Zhang, Pretreatment of corn stover with diluted acetic acid for enhancement of acidogenic fermentation, Bioresource Technology, 158 (2014): 12-8 